\title{
Transmission dynamics of an iridescent virus in an experimental mosquito population: the role of host density
}

\author{
CARLOS F. MARINA ${ }^{1,2}$, ILDEFONSO FERNÁNDEZ-SALAS ${ }^{3}$, JORGE $^{-}$ \\ E. IBARRA ${ }^{4}$, JUAN I. ARREDONDO-JIMÉNEZ ${ }^{2}$, JAVIER VALLE ${ }^{1}$ and \\ TREVOR W I L L I A M S ${ }^{1,5}{ }^{1}$ ECOSUR, Tapachula, Mexico, ${ }^{2}$ Centro de Investigación de Paludismo-INSP, \\ Tapachula, Mexico, ${ }^{3}$ Facultad de Ciencias Biológicas, Universidad Autónoma de Nuevo León, San Nicolás de los Garza, \\ Mexico, ${ }^{4}$ CINVESTAV-IPN, Irapuato, Mexico and ${ }^{5}$ Departamento de Producción Agraria, Universidad Pública de Navarra, \\ Pamplona, Spain
}

\begin{abstract}
The transmission of insect pathogens cannot be adequately described by direct linear functions of host and pathogen density due to heterogeneity generated from behavioural or physiological traits, or from the spatial distribution of pathogen particles. Invertebrate iridescent viruses (IIVs) can cause patent and lethal infection or a covert sub-lethal infection in insects. Aedes aegypti larvae were exposed to suspensions of IIV type 6 at two densities. High larval density increased the prevalence of aggression resulting in potentially fatal wounding.

2. The overall prevalence of infection (patent + covert) was positively influenced by host density and increased with exposure time in both densities. The survival time of patently infected insects was extended by $\approx 5$ days compared with non-infected insects.

3. Maximum likelihood models based on the binomial distribution were fitted to empirical results. A model incorporating heterogeneity in host susceptibility by inclusion of a pathogen-free refuge was a significantly better fit to data than an all-susceptible model, indicating that transmission is non-linear. The transmission coefficient (v) did not differ with host density whereas the faction of the population that occupied the pathogen-free refuge $\left(\Pi_{R}\right)$ was significantly reduced at high host density compared with the low density treatment.

4. The transmission of free-living infective stages of an IIV in Ae. aegypti larvae is non-linear, probably because of density-related changes in the frequency of aggressive encounters between hosts. This alters host susceptibility to infection and effectively reduces the proportion of hosts that occupy the pathogen-free refuge.
\end{abstract}

Key words. Aedes aegypti, aggression, infection, non-linear transmission, pathogenfree refuge.

Correspondence: Trevor Williams, Departamento de Producción Agraria, Universidad Pública de Navarra, Pamplona 31006, Spain. E-mail: trevor.williams@unavarra.es

\section{Introduction}

Pathogens can have a major influence on the dynamics of certain insect populations (Myers \& Rothman, 1996; Dwyer \& Hails, 2002). The reproductive rate of pathogens and their impact on host populations depends critically on their rate of transmission from infected to susceptible hosts. 
For pathogens with free-living infective stages, transmission will depend on the frequency of contact between host and pathogen particles (Goulson et al., 1995). Clearly the probability of contact depends on the densities of susceptible hosts and infective pathogen particles. Insect pathogen models developed from the original models of Anderson and May (1981) assume that the probabilities of contact and acquisition of an infection per unit time can be described by a single constant, $v$, the transmission coefficient. This assumption is based on the 'mass-action principle' and implies that transmission is a direct linear function of host and pathogen density which is an invariant characteristic for each host-pathogen system.

Theoretical studies supported by empirical observations indicate that viral pathogens of Lepidoptera do not obey the mass-action principle (Hochberg, 1991). Specifically, the transmission coefficient has been shown to vary in a non-linear manner with host and pathogen density (D'Amico et al., 1996; Knell et al., 1996, 1998). Heterogeneity in host susceptibility can also generate nonlinearities in the probability of transmission (Dwyer et al., 1997; Reeson et al., 2000). Recently, Hails et al. (2002) have addressed non-linear patterns of transmission by considering that a fraction of the surviving host population may not come into contact with an infective dose of pathogen or may be innately resistant to infection. This sub-population occupies a pathogen-free refuge, the size of which may vary according to host or pathogen densities.

Invertebrate iridescent viruses (IIVs) (Iridoviridae) are non-occluded icosahedral particles with a DNA genome that infect invertebrates, especially insects in aquatic habitats (Williams et al., 2000). IIVs can cause two types of infection (Williams, 1995; Tonka \& Weiser, 2000). Patent infection results in an obvious blue coloration of immature stages followed later by death, whereas covert infection is not obvious and infected insects can develop to the adult stage and may reproduce. However, covertly infected adults may suffer a reduction in body size, longevity, and reproductive capacity (Marina et al., 1999, 2003b) and such sublethal effects can have a major influence on the population dynamics of insect populations (Boots et al., 2003). Covert infections can be detected using a highly sensitive insect bioassay or polymerase chain reaction techniques (Williams, 1993).

The route of infection of IIVs is generally uncertain. IIVs are not highly infectious by ingestion (Carter, 1973b; Marina et al., 2003c) but cannibalism, aggressive interactions, and vector-mediated transmission by parasites have been observed to be important in experimental invertebrate populations (Carter, 1973a; Grosholz, 1992; Mullens et al., 1999; López et al., 2002).

The need for studies of density-dependent changes in the transmission efficacy of pathogens in diverse insect-pathogen systems is explicitly recognised (Reeson et al., 2000). The present study was designed to examine the effect of host-density on the transmission of Invertebrate iridescent virus 6 (IIV-6) in the larvae of the mosquito, Aedes aegypti. Aggression among conspecific mosquito larvae is often increased at high densities (Koenekoop \& Livdahl, 1986; Edgerly et al., 1999). IIV-6 particles released into water following the breakdown of infected cadavers can remain infective for extended periods (weeks to months) if not exposed to direct sunlight or very high temperatures (A. Hernández, unpublished data). The present study therefore examined the transmission dynamics of a non-occluded virus at two host densities in an insect with aquatic immature stages.

\section{Methods}

Insects and virus

Eggs of Ae. aegypti were obtained from a laboratory colony that is continuously reared in the Centro de Investigación de Paludismo, Tapachula, Chiapas, Mexico. Larvae were reared in groups of 500 from these eggs using filtered de-chlorinated water and a diet of powdered soya and yeast. Larvae of Galleria mellonella were obtained from a laboratory culture maintained on a semisynthetic diet in El Colegio de la Frontera Sur (ECOSUR), Tapachula, Chiapas, Mexico. All insects were maintained in a controlled room temperature of $25 \pm 1{ }^{\circ} \mathrm{C}, 75-85 \% \mathrm{RH}$, and L:D $12 \mathrm{~h}: 12 \mathrm{~h}$.

An isolate of Invertebrate iridescent virus 6 (IIV-6) (genus Iridovirus, Family Iridoviridae) was produced by injection in third-instar G. mellonella as described previously (Constantino et al., 2001). At $\approx 10$ days post-infection, patently infected G. mellonella larvae were placed at $-20{ }^{\circ} \mathrm{C}$ and stored until required. To purify IIV-6, infected larvae were triturated in $1 \mathrm{ml}$ sterile distilled water and subjected to three steps of centrifugation at $490 \mathrm{~g}$ for $10 \mathrm{~min}, 15300 \mathrm{~g}$ for $10 \mathrm{~min}$, followed by a $30 \%$ (wt/vol.) sucrose cushion at $15300 \mathrm{~g}$ for $30 \mathrm{~min}$ and two washes in sterile water as described by Marina et al. $(2003 \mathrm{a}, \mathrm{b})$. The purified suspension was quantified by direct counting of a mixture of virus and $460 \mathrm{~nm}$ diameter polystyrene beads (Aldrich Chemical Co., St. Louis, Missouri) using a scanning electron microscope (Constantino et al., 2001).

\section{Inoculation of mosquito larvae}

Groups of 50 and 500 third and fourth instar Ae. aegypti were placed in plastic cups containing $100 \mathrm{ml}$ of a suspension of $1.9 \times 10^{9}$ particles $\mathrm{ml}^{-1}$ for periods of $1,6,12$, and $24 \mathrm{~h}$ (eight groups in total). Four groups of 500 larvae incubated in clean water served as controls for virus contamination at each time point. Following exposure to the virus, 50 larvae from each group (representing the entire group of 50, or a random sample of the group of 500) were individually passed through five sequential 1-litre volumes of clean de-chlorinated water to eliminate residues of the inoculum (Marina et al., 1999). Each larva was then placed individually into a plastic cup containing $10 \mathrm{ml}$ water and reared on a powdered yeast and soya diet until adult 
emergence. Signs of patent IIV disease indicated by an iridescent blue colour in the epidermis were noted during twice daily inspections, as were the numbers of living and dead larvae, pupation, and adult emergence. Following eclosion, adult mosquitoes were sexed, individually frozen and stored at $-20{ }^{\circ} \mathrm{C}$ until required. The procedure was performed four times.

\section{Bioassay to detect covert infections}

To determine the prevalence of covert IIV infections 50 adult mosquitoes per replicate per density treatment per time point were thawed and the abdomen was removed and placed in a microcentrifuge tube containing $300 \mu \mathrm{l}$ aureomycin solution $(0.08 \% \mathrm{wt} / \mathrm{vol}$.). Each abdomen was homogenised using a sterile plastic pipette tip and subjected to centrifugation at $190 \mathrm{~g}$ for $5 \mathrm{~min}$ to pellet the insect debris. Volumes of $8.4 \mu \mathrm{l}$ of the supernatant were injected into groups of 15 third-instar G. mellonella using a manual microinjector (Burkard Ltd, Rickmansworth, U.K.). Injected $G$. mellonella were placed in plastic cups containing a semisynthetic diet and reared for 12-14 days, after which they were checked for signs of patent IIV infection, indicative of the presence of a covert infection of the original mosquito adult (Williams, 1995). Identical procedures were performed with control mosquitoes at all time points.

\section{Statistical procedures}

The prevalence of infection was subjected to analysis of variance (ANOVA) using the Generalised Linear Interactive Modelling (GLIM) program (Numerical Algorithms Group, 1993) with a binomial error distribution specified and density as a factor and exposure time as a continuous variable. Minor overdispersion was taken into account by scaling the error distribution (scale parameter $=2.09$ ). Survival time of mosquitoes at each density was analysed using a Weibull distribution in GLIM (Crawley, 1993).

The probability of becoming infected was estimated using maximum-likelihood models based on the binomial distribution (Hails et al., 2002). First, a simple model was examined that assumes that all individuals in the population are equally susceptible to infection during the period of exposure to the pathogen. The probability that individuals become infected given that they survive any other sources of mortality is:

$$
\text { probability of infection }=1-\mathrm{e}^{-\mathrm{v} P_{0} t},
$$

where $v$ is the transmission coefficient, $P_{0}$ is the density of the pathogen at the start of the experiment, and $t$ is the time interval (in hours) between the start of the experiment and the moment at which the larvae were removed from the virus suspension and washed. Subsequent rearing in the laboratory determined whether or not the insects had acquired an infection. This model was compared with a simple means model, a null model for which a mean value is fitted for each density over time. An alternative model includes heterogeneity in transmission by allowing a portion of the insects to occupy a refuge wherein they are not exposed to an infective dose of virus or are physiologically resistant to infection. In this situation, the probability of becoming infected given survival is:

$$
\text { probability of infection }=\left(1-\mathrm{e}^{-v P_{0} t}\right) \times\left(1-\Pi_{\mathrm{R}}\right),
$$

where $\Pi_{R}$ represents the degree of heterogeneity in the population, i.e. the fraction of the population that occupy the pathogen-free refuge. Parameter estimation was performed in S-Plus (Crawley, 2002) and model simplification, by sequential removal of terms from the full refuge model, was undertaken as described by Hails et al. (2002). Models were corrected for minor overdispersion (scale parameter $=2.27$ ).

Non-virus mortality was analysed by contingency tables. The interval between exposure to inoculum and adult emergence was subjected to analysis of covariance with sample size as a covariable. Mean separation was performed by Tukey's test. In all cases, assumptions of normality, homoscedasticity, and the distribution of residuals were examined in each analysis.

\section{Results}

Immature (larva + pupa) mosquito mortality, due to causes other than virus infection, was significantly higher in insects from the high density treatment $(6.9 \%)$ compared with the low density treatment $(4.3 \%)$ when summed over all exposure times $\left(\chi_{1}^{2}=5.32, P=0.021\right)$, indicating that high larval density results in aggression and increases the risk of potentially fatal wounding. The prevalence of patent infections was very low $(=1 \%)$ in larvae exposed for 1 or $6 \mathrm{~h}$ in both densities. Following 12-24 h exposure, the prevalence of patent infection increased to $4 \%$ at low density and $11.5 \%$ at the high density. In contrast, covert infections detected by bioassay of adult mosquitoes ranged from 2.1 to $5.6 \%$ at the low density and $9.8-23.2 \%$ at the high density treatment. This resulted in an overall incidence of infection (patent + covert) that was significantly higher in the high density treatment than at the low density $\left(F_{1,31}=14.0, P<0.001\right.$, scale parameter $\left.=2.09\right)($ Fig. 1$)$. The prevalence of infection increased over time at both densities $\left(F_{1,30}=6.70, P=0.015\right.$, scale parameter $=$ 2.09). No infections, patent or covert (from G. mellonella bioassays), were observed in control larvae.

The transmission coefficient values estimated for the allsusceptible model were $v_{1}=0.005678$ at low density and $v_{2}=0.025971$ at high density (Fig. 2). This model was a significantly better fit than a simple means null model $\left(\chi_{1}^{2}=93.6, \quad P<0.001\right)$. However, the all-susceptible model was a significantly poorer fit than the refuge model $\left(\chi^{2}{ }_{1}=28.2, P<0.001\right)$, for which the parameter estimates were $v_{1}=0.560794$ and $\Pi_{\mathrm{R} 1}=0.931101$ at low density and $v_{2}=0.154228$ and $\Pi_{\mathrm{R} 2}=0.654213$ at high density. Model simplification indicated that the transmission terms 


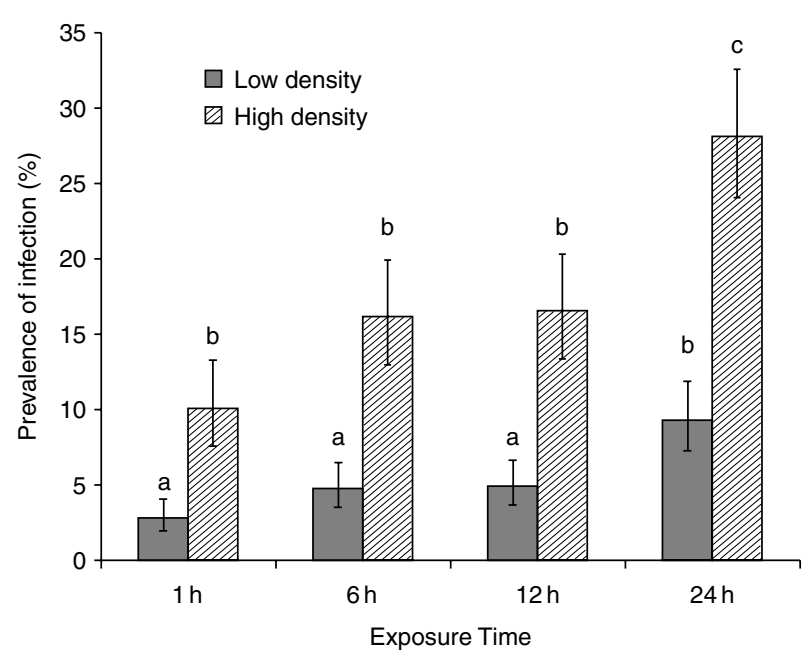

Fig. 1. Prevalence of total infection (patent + covert) in mosquito larvae exposed to iridescent virus at low $(50$ insects per $100 \mathrm{ml})$ and high (500 insects per $100 \mathrm{ml}$ ) densities for periods between 1 and $24 \mathrm{~h}$. Vertical bars indicate asymmetrical $95 \% \mathrm{CL}$ values. Columns headed by the same letter are not significantly different (GLIM scaled binomial error distribution, $P>0.05$ ).

were not significantly different $\left(\chi^{2}{ }_{1}=1.34, P=0.24\right)$, indicating that the rate of acquisition of infection did not differ between densities, whereas the refuge parameter was significantly greater at low density than at high density $\left(\chi^{2}{ }_{1}=15.8, P<0.001\right)$. Accordingly, the parameter values of the minimum significant model were $v=0.39189$, $\Pi_{R 1}=0.927396$ and $\Pi_{R 2}=0.727014$. The resulting curve of probability of infection over time increases rapidly from 1 to $3 \mathrm{~h}$ after exposure to inoculum before levelling off at

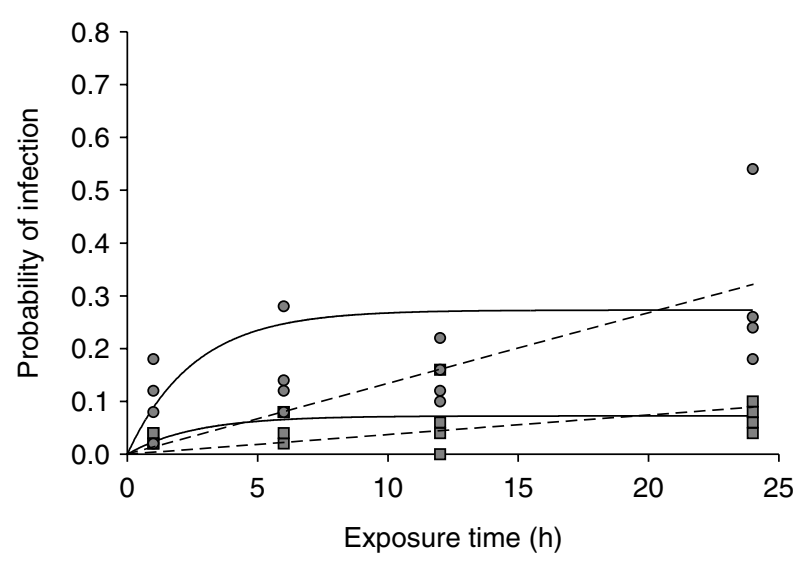

Fig. 2. The probability of Aedes aegypti larvae becoming infected by IIV-6 with increasing exposure time in hours. Data points are values for each replicate. The upper and lower dashed lines indicate the fit of the all-susceptible model for the high (circles) and low (squares) densities respectively. The upper and lower solid curves indicate the fit of the minimum significant pathogen-free refuge model for the high and low densities respectively. both densities (Fig. 2). The steady-state probability of infection given prolonged exposure to inoculum $(=6 \mathrm{~h})$ was approximately four-fold greater at the high host density than at low density.

The mean time to death of those larvae that died following exposure to IIV-6 at each density was $\approx 5$ days greater than that of control larvae $\left(\chi_{1}^{2}=89.1, \quad P<0.001\right)$ (Fig. 3a). When times to death of patently infected larvae from both density treatments were pooled and compared as a group with control and virus-exposed insects (comprising non-infected and covertly infected individuals that could not be distinguished during the larval stage) it became apparent that patent infection greatly increased mean times until death (Fig. 3b) $\left(\chi_{1}^{2}=117.5, P<0.001\right)$.
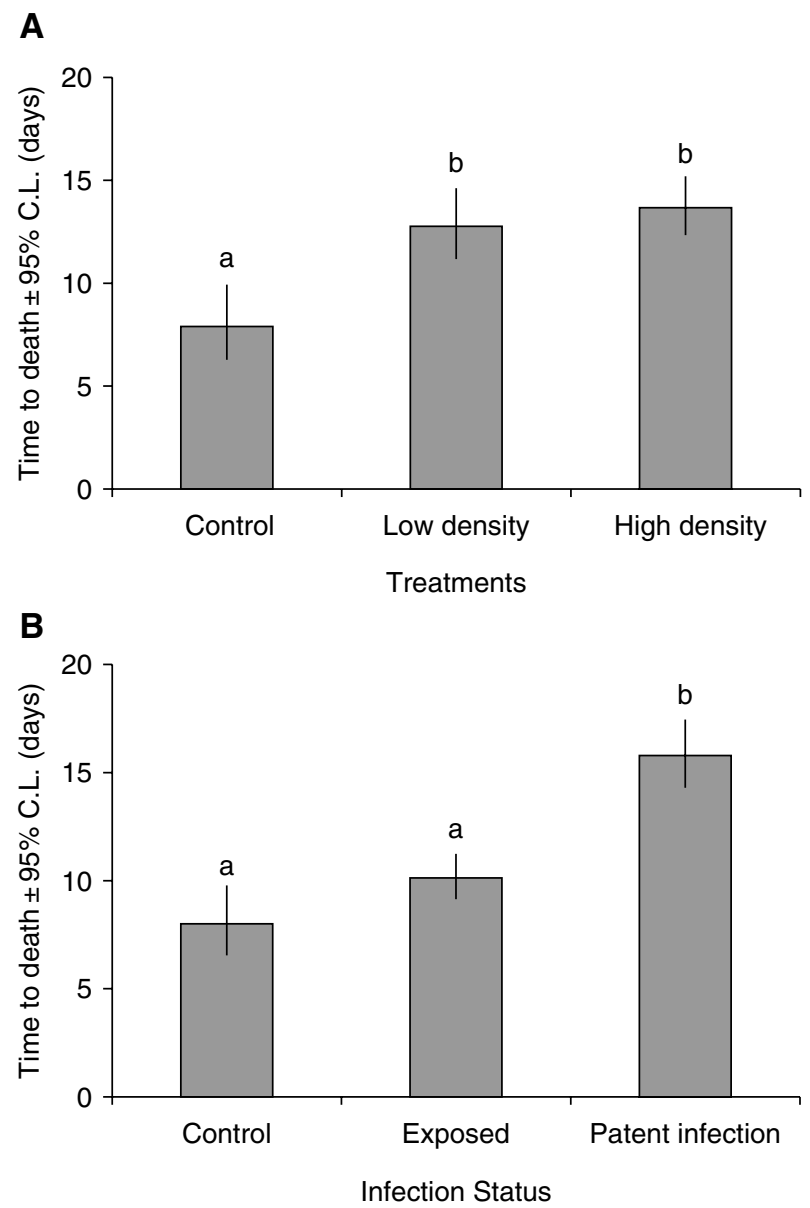

Fig. 3. Mean time to death of mosquito larvae (a) when exposed to iridescent virus in low and high density groups and control larvae not exposed to virus and (b) when larvae are pooled according to infection status: patently infected, exposed to virus inoculum but not patently infected, and control insects. Columns headed by identical letters are not significantly different (Weibull analysis in GLIM, $P>0.05$ ). 


\section{Discussion}

The transmission process is critical to understanding insect pathogen dynamics (Dwyer, 1991; Swinton et al., 2002; Hails et al., 2002). Virus transmission in the aquatic life stages of insects is very poorly understood. This is believed to be the first study on transmission rates of a virus pathogen of the aquatic stages of an insect, despite the major influence that certain pathogens can exert on the dynamics of aquatic insect populations (Kohler \& Hoiland, 2001). In this study, a negative relationship was observed between density and survival of Ae. aegypti larvae, probably due to an increase in aggressive interactions among larvae at high densities (Clements, 1992).

Exposure to the virus more commonly resulted in covert infection rather than patent, lethal disease. Laboratory studies on the Ae. aegypti-IIV-6 system have consistently observed that covert infections are $\approx 10$-fold more prevalent than patent infections (Marina et al., 1999, 2003a,b,c). The ratio of covert : patent infections is orders of magnitude greater in certain natural aquatic insect populations infected by IIVs (Williams, 1995; Tonka \& Weiser, 2000). However, it is not clear whether covert infection alters the vulnerability of larvae to aggression by conspecifics. Given that the period of exposure to inoculum was relatively brief $(\leq 24 \mathrm{~h})$, it seems unlikely that the early stages of a sublethal infection would cause debilitating effects within such a short interval of time.

Reproductive success in microparasites is defined by the number of hosts that become infected by the progeny generated from each primary infected host. It was therefore appropriate to consider patently and covertly infected hosts as a group representing the total number of individuals that acquired infection following exposure to inoculum. This is because the process of horizontal transmission is independent from the process of pathogenesis in the host that acquires the disease. Clearly, only the covertly infected insects represent opportunities for vertical transmission of these viruses. Vertical transmission has been observed in the mosquito Ochlerotatus taeniorhynchus infected with IIV-3 but has not been studied in detail (Linley \& Nielsen, 1968; Woodard \& Chapman, 1968).

Host density had a positive influence on the transmission of IIV-6, probably due to an increase in the frequency of aggression at high densities. However, simple linear functions were not sufficient to describe the transmission process due to a significant degree of heterogeneity in host susceptibility to infection. The rate of acquisition of infection (v) was similar at both host densities but the proportion of the population in the pathogen-free refuge $\left(\Pi_{R}\right)$ was significantly reduced at high host density, i.e. transmission increased with host density because a greater proportion of the population was susceptible.

Positive relationships between transmission and host density have also been observed in directly transmitted bacterial and viral pathogens of the moth Plodia interpunctella, although in both cases the transmission coefficient decreased with increasing pathogen density (Knell et al.,
1996, 1998). A similar pattern has been reported for a nucleopolyhedrovirus of the cabbage moth, Mamestra brassicae (Vasconcelos, 1996). In contrast, the transmission coefficient of the gypsy moth nucleopolyhedrovirus declined with increasing densities of both host and pathogen (D'Amico et al., 1996).

Heterogeneity in host susceptibility to viral diseases is well recognised in natural insect populations (Dwyer et al., 1997, 2002) and in laboratory populations subjected to crowding during early larval development (Goulson \& Cory, 1995; Reeson et al., 2000). Such heterogeneity appears responsible for generating non-linearities in transmission by directly influencing the probability that contact between pathogen and hosts results in infection. However, as mosquito larvae were immersed in IIV suspension in the present study, there was no possibility that a heterogeneous spatial distribution of infectious particles could be responsible for generating the observed non-linearities in transmission, unlike the studies on baculoviruses of Lepidoptera (D'Amico et al., 1996; Hails et al., 2002). Instead, transmission was dependent on the size of the pathogen refuge in mosquito larvae determined by the behaviour of the host and the density-mediated tendency for aggressive encounters with conspecifics.

In studies with wild-type and genetically modified baculoviruses capable of infecting two species of moths, the pathogen-free refuge was estimated to be very large, accounting for $78-99 \%$ of the host population, depending on host species and type of virus (Hails et al., 2002), which is remarkably similar to the values (73-93\%) estimated in the present study. Pathogen-free refuges are also highly influential in determining the stability of insect pathogen dynamics, although the magnitude and direction of the stabilising effect depends on how the size of the refuge varies with host and pathogen densities (Dwyer et al., 1997; White \& Wilson, 1999).

The importance of pathogens in the population dynamics of aquatic invertebrates is poorly understood. Densitydependent transmission of spores and density-dependent spore production in infected hosts was observed in Glugoides (Pleistophora) intestinales, a microsporidian parasite of Daphnia magna (Ebert, 1995). Strong evidence for cyclic, delayed density-dependent mortality of caddisfly larvae caused by a microsporidian disease was detected in a 15-year study in Michigan, U.S.A. (Kohler \& Hoiland, 2001). In contrast, microsporidian infection of the mosquito Aedes stimulans had little impact on the host population and persisted as a low prevalence, enzootic disease, transmitted from parent to progeny, with opportunities for horizontal transmission limited by the availability of intermediate copepod hosts (Andreadis, 1999).

Interestingly, patent IIV infection resulted in a clear increase in the mean time to death. The time to death of an infected insect represents a virulence trade-off between time taken to exploit each infected host for maximal production of progeny particles and rapid kill of each host, with reduced progeny production, to maximise the rate at which infections can be transmitted. A number of 
baculoviruses express genes such as egt that manipulate host hormone titres to extend the lifespan of infected hosts, thereby increasing the yield of viral progeny from each infected insect (O'Reilly, 1995). Deletion of these genes results in reduced survival time of infected hosts and a concurrent reduction in the per capita yield of the virus (O'Reilly \& Miller, 1991; Wilson et al., 2000) and therefore a reduced probability of transmission (Dushoff \& Dwyer, 2001). Although a number of apoptosis inhibitors have been identified in the IIV-6 genome that are designed to prevent the programmed suicide of infected cells (Jakob et al., 2001), no endocrine hormone regulating genes such as egt homologues have yet been identified in IIVs.

Patent IIV infection of isopods, Diptera, Lepidoptera, and Coleoptera invariably results in extended survival times. As a result, the productivity of IIV particles per gram of patently infected host tissue is greater than that of any other type of insect virus (Williams \& Smith, 1957; Williams, 1996). Extended survival times of infected hosts may also increase the probability of transmission by cannibalism, predation, or parasite-mediated vectoring. Patently infected hosts also become lethargic, again increasing the likelihood of becoming a victim of cannibalism or attack by parasites (Carter, 1973a; López et al., 2002).

In summary, the transmission of IIV-6 in Ae. aegypti was observed to be highly non-linear but was adequately described by including a pathogen-free refuge to account for differences in host susceptibility to infection. The probability of acquiring infection, indicated by the transmission coefficient (v), was similar at high and low density but the fraction of the host population occupying the refuge was significantly reduced at high density leading to a greater overall probability of becoming infected. The importance of the refuge was probably determined by density-related changes in the frequency of aggressive encounters between hosts. The role of pathogen-free refuges in describing the heterogeneity inherent in the transmission dynamics of IIVs merits systematic examination across a range of host and pathogen densities.

\section{Acknowledgements}

We thank Luis Alberto García for technical assistance, Guadalupe Nieto for electron microscopy, and Alma Delia López, Francisco Solis, Américo Rodríguez, and Alvaro Hernández for the supply of insects, and an anonymous reviewer for suggesting the use of non-linear transmission models. This work was supported by a CONACyT doctoral scholarship to C.F.M. and a Plan Tecnológico de Navarra travel grant to T.W.

\section{References}

Anderson, R.M. \& May, R.M. (1981) The population dynamics of microparasites and their invertebrate hosts. Philosophical
Transactions of the Royal Society London, Series B, 291, 451-524.

Andreadis, T.G. (1999) Epizootiology of Amblyospora stimuli (Microsporidiida: Amblyosporidae) infections in field populations of a univoltine mosquito, Aedes stimulans (Diptera: Culicidae), inhabiting a temporary vernal pool. Journal of Invertebrate Pathology, 74, 198-205.

Boots, M., Greenman, J., Ross, D., Norman, R., Hails, R. \& Sait, S. (2003) The population dynamical implications of covert infections in host-microparasite interactions. Journal of Animal Ecology, 72, 1064-1072.

Carter, J.B. (1973a) The mode of transmission of Tipula iridescent virus. I. Source of infection. Journal of Invertebrate Pathology, 21, 123-130.

Carter, J.B. (1973b) The mode of transmission of Tipula iridescent virus. II. Route of infection. Journal of Invertebrate Pathology, 21, 136-143.

Clements, A.N. (1992) Growth and development. The Biology of Mosquitoes (ed. by A. N. Clements), pp. 150-170. Chapman \& Hall, London.

Constantino, M., Christian, P., Marina, C.F. \& Williams, T. (2001) A comparison of techniques for detecting Invertebrate iridescent virus 6. Journal of Virological Methods, 98, 109-118.

Crawley, M.J. (1993) GLIM for Ecologists. Blackwell, Oxford, U.K.

Crawley, M.J. (2002) Statistical Computing: an Introduction to Data Analysis Using S-Plus. John Wiley, London.

D’Amico, V., Elkinton, J.S., Dwyer, G., Burand, J.P. \& Buonaccorsi, J.P. (1996) Virus transmission in gypsy moth is not a simple mass action process. Ecology, 77, 201-206.

Dushoff, J. \& Dwyer, G. (2001) Evaluating the risks of engineered viruses: modeling pathogen competition. Ecological Applications, 11, 1602-1609.

Dwyer, G. (1991) The roles of density, stage and patchiness in the transmission of an insect virus. Ecology, 72, 559-574.

Dwyer, G., Dushoff, J., Elkinton, J.S., Burand, J.P. \& Levin, S.A. (2002) Variation in susceptibility: lessons from an insect virus. Adaptive Dynamics of Infectious Diseases: in Pursuit of Virulence Management (ed. by U. Dieckmann, J. A. J. Metz, M. W. Sabelis and K. Sigmund), pp. 74-84. Cambridge University Press, Cambridge.

Dwyer, G., Elkinton, J.S. \& Buonaccorsi, J.P. (1997) Host heterogeneity in susceptibility and disease dynamics: tests of a mathematical model. American Naturalist, 150, 685-707.

Dwyer, G. \& Hails, R.S. (2002) Manipulating your host: hostpathogen population dynamics, host dispersal and genetically modified baculoviruses. Dispersal Ecology (ed. by J. M. Bullock, R. E. Kenward and R. S. Hails), pp. 173-193. Blackwell, Oxford.

Ebert, D. (1995) The ecological interactions between a microsporidian parasite and its host Daphnia magna. Journal of Animal Ecology, 64, 361-369.

Edgerly, J.S., Willey, M.S. \& Lidvahl, T. (1999) Intraguild predation among larval treehole mosquitoes, Aedes albopictus, Ae. aegypti, and Ae. triseriatus (Diptera: Culicidae), in laboratory microcosms. Journal of Medical Entomology, 36, 394-399.

Goulson, D. \& Cory, J.S. (1995) Responses of Mamestra brassicae (Lepidoptera: Noctuidae) to crowding: interactions with disease resistance, colour phase, and growth. Oecologia, 104, 416-423.

Goulson, D., Hails, R.S., Williams, T., Hirst, M.L., Vasconcelos, S.D., Green, B.M. et al. (1995) Transmission dynamics of a virus in a stage-structured insect population. Ecology, 76, 392-401. 
Grosholz, E.D. (1992) Interactions of intraspecific, interspecific, and apparent competition with host-pathogen population dynamics. Ecology, 73, 507-514.

Hails, R.S., Hernández-Crespo, P., Sait, S.M., Donnelly, C.A., Green, B.M. \& Cory, J.S. (2002) Transmission patterns of natural and recombinant baculoviruses. Ecology, 83, 906-916.

Hochberg, M.E. (1991) Non linear transmission rates and the dynamics of infectious disease. Journal of Theoretical Biology, 153, 301-321.

Jakob, N.J., Muller, K., Bahr, U. \& Darai, G. (2001) Analysis of the first complete DNA sequence of an invertebrate iridovirus: coding strategy of the genome of Chilo iridescent virus. Virology, 286, 182-196.

Knell, R.J. Begon, M. \& Thompson, D.J. (1996) Transmission dynamics of Bacillus thuringiensis infecting Plodia interpunctella: a test of the mass action assumption with an insect pathogen. Proceedings of the Royal Society London, Series B, 263, 75-81.

Knell, R.J., Begon, M. \& Thompson, D.J. (1998) Host-pathogen population dynamics, basic reproductive rates, and threshold densities. Oikos, 81, 299-308.

Koenekoop, R. \& Livdahl, T. (1986) Cannibalism among Aedes triseriatus larvae. Ecological Entomology, 11, 111-114.

Kohler, S.L. \& Hoiland, W.K. (2001) Population regulation in an aquatic insect: the role of disease. Ecology, 82, 2294-2305.

Linley, J.R. \& Nielsen, H.T. (1968) Transmission of a mosquito iridescent virus in Aedes taeniorhynchus. I. Laboratory experiments. Journal of Invertebrate Pathology, 12, 7-16.

López, M., Rojas, J.C., Vandame, R. \& Williams, T. (2002) Parasitoid-mediated transmission of an iridescent virus. Journal of Invertebrate Pathology, 80, 160-170.

Marina, C.F., Arredondo-Jiménez, J., Castillo, A. \& Williams, T. (1999) Sublethal effects of iridovirus disease in a mosquito. Oecologia, 119, 383-388.

Marina, C.F., Arredondo-Jiménez, J.I., Ibarra, J.E., FernándezSalas, I. \& Williams, T. (2003a) Effects of an optical brightener and an abrasive on iridescent virus infection and development of Aedes aegypti. Entomologia Experimentalis et Applicata, 109, $155-161$.

Marina, C.F., Ibarra, J.E., Arredondo-Jiménez, J.I., FernándezSalas, I., Liedo, P. \& Williams, T. (2003b) Adverse effects of covert iridovirus infection on life history and demographic parameters of Aedes aegypti. Entomologia Experimentalis et Applicata, 106, 53-61.

Marina, C.F., Ibarra, J.E., Arredondo-Jiménez, J.I., FernándezSalas, I., Valle, J. \& Williams, T. (2003c) Sublethal iridovirus disease of the mosquito Aedes aegypti is due to viral replication not cytotoxicity. Medical and Veterinary Entomology, 17, 187-194.

Mullens, B.A., Velten, R.K. \& Federici, B.A. (1999) Iridescent virus infection in Culicoides variipennis sonorensis and interactions with the mermithid parasite Heleidomermis magnapapula. Journal of Invertebrate Pathology, 73, 231-233.

Myers, J.H. \& Rothman, L.D. (1996) Virulence and transmission of infectious diseases in humans and insects: evolutionary and demographic patterns. Trends in Ecology and Evolution, 10, 194-198.

Numerical Algorithms Group (1993) The GLIM System: Release 4 Manual (ed. by B. Francis, M. Green and C. Payne). Clarendon Press, Oxford.

O'Reilly, D.R. (1995) Baculovirus-encoded ecdysteroid UDPglucosyl-transferase. Insect Biochemistry and Molecular Biology, 26, 541-550.

O'Reilly, D.R. \& Miller, L.K. (1991) Improvement of a baculovirus pesticide by deletion of the egt gene. Bio/Technology, 9, 1086-1089.

Reeson, A.F., Wilson, K., Cory, J.S., Hankard, P., Weeks, J.M., Goulson, D. et al. (2000) Effects of phenotypic plasticity on pathogen transmission in the field in a Lepidoptera-NPV system. Oecologia, 124, 373-380.

Swinton, J., Woolhouse, M.E.J., Begon, M.E., Dobson, A.P., Ferroglio, E., Grenfell, B.T. et al. (2002) Microparasite transmission and persistence. The Ecology of Wildlife Diseases (ed. by P. J. Hudson, A. Rizzoli, B. T. Grenfell, H. Heesterbeek and A. P. Dobson), pp. 83-101. Oxford University Press, Oxford.

Tonka, T. \& Weiser, J. (2000) Iridovirus infection in mayfly larvae. Journal of Invertebrate Pathology, 76, 229-231.

Vasconcelos, S.D. (1996) Studies on the transmission and dispersal of baculoviruses in lepidopteran populations. $\mathrm{PhD}$ thesis, Department of Zoology, University of Oxford.

White, K.A.J. \& Wilson, K. (1999) Modelling density-dependent resistance in insect-pathogen interactions. Theoretical Population Biology, 56, 163-181.

Williams, T. (1993) Covert iridovirus infection of blackfly larvae. Proceedings of the Royal Society London, Series B, 251, 225-230.

Williams, T. (1995) Patterns of covert infection by invertebrate pathogens: iridescent viruses of blackflies. Molecular Ecology, 4, 447-457.

Williams, T. (1996) The iridoviruses. Advances in Virus Research, 46, 345-412.

Williams, T., Chinchar, V.G., Darai, G., Hyatt, A., Kalmakoff, J. \& Seligy, V. (2000) Iridoviridae. Virus Taxonomy, 7th Report of the International Committee on Taxonomy of Viruses (ed. by M. H. V. van Regenmortel, C. M. Fauquet, D. H. L. Bishop, E. B. Carstens, M. K. Estes, S. M. Lemon et al. ), pp. 167-182. Academic Press, New York.

Williams, R.C. \& Smith, K.M. (1957) A crystallizable insect virus. Nature, 179, 119-120.

Wilson, K.R., O’Reilly, D.R., Hails, R.S. \& Cory, J.S. (2000) Agerelated effects of the Autographa californica multiple nucleopolyhedrosis egt gene in the cabbage looper (Trichoplusia ni). Biological Control, 19, 57-63.

Woodard, D.B. \& Chapman, H.C. (1968) Laboratory studies with the mosquito iridescent virus (MIV). Journal of Invertebrate Pathology, 11, 296-301.

Accepted 2 November 2004 